\title{
Prevalence of Common Clinically Manifested Developmental Anomalies of the Oral Cavity Among Adults - An Epidemiological Study in a South Indian Population
}

\author{
Lokesh Sundaram $^{1}$, Vidhya Rathnavelu ${ }^{2}$, Divyambika C. Venugopal ${ }^{3}$, Malathi Narasimhan ${ }^{2}$, Mythili \\ Sabesan $^{4}$, Swarna Swetha ${ }^{1}$ \\ 1. Dentistry, Sri Ramachandra Institute of Higher Education and Research, Chennai, IND 2. Oral Pathology and \\ Microbiology, Sri Ramachandra Institute of Higher Education and Research, Chennai, IND 3. Oral Medicine and \\ Radiology, Sri Ramachandra Institute of Higher Education and Research, Chennai, IND 4. Oral Pathology, Sri \\ Ramachandra Institute of Higher Education and Research, Chennai, IND
}

Corresponding author: Mythili Sabesan, sabesanm@hotmail.com

\section{Abstract \\ Introduction}

Developmental anomalies are malformation which arises due to the disturbances during the development of the organs. Although there have been many studies that have described the prevalence of these anomalies in the oral cavity, none have specified the prevalence of clinically manifested anomalies and their distribution between gender.

\section{Materials and methods}

In this study, 500 patients aged 18 to 50 years were screened for clinically manifested developmental anomalies. These were then divided based on age, sex, and jaws, which were then analyzed using a chisquare test and tabulated.

\section{Results}

We detected anomalies in $12.2 \%$ of the study population. Supernumerary teeth were the most prevalent anomaly detected (4.25\%). The frequency of developmental anomalies was higher in men (57.1\%).

\section{Conclusions}

Supernumerary teeth were the most widely recognized anomaly. Other anomalies identified were related to the shape and size of teeth. These anomalies can lead to severe orofacial problems. Therefore, proper care of these anomalies should be taken.

Received 08/04/2020

Review began 08/05/2020 Review ended 08/07/2020 Published 08/23/2020

() Copyright 2020

Sundaram et al. This is an open access article distributed under the terms of the Creative Commons Attribution License CC-BY 4.0., which permits unrestricted use, distribution, and reproduction in any medium, provided the original author and source are credited.
Categories: Pathology, Epidemiology/Public Health

Keywords: developmental anomalies, oro-facial problems, inheritance, mutations, prevalence

\section{Introduction}

Developmental anomalies comprise a wide range of abnormalities of body structures or functions and are present at birth or of parental origin [1]. The causes of the appearance of these defects are many. They can be genetic factors such as inheritance, mutation, or different errors at the hereditary level. Likewise, they can be ecological factors that incorporate physical, chemical, or organic elements that cause changes in genes, leading to altered signaling, resulting in the manifestation of developmental anomalies [2,3]. Irregularities relating to tooth size and shape result from disturbances that happen in the morpho-differentiation phase of fetal development. Other defects, like ectopic eruption or impaction, are a result of developmental disturbances that have occurred in the eruption sequence of permanent dentition [4-6].

The degree of prevalence of developmental anomalies of the oral cavity, or any developmental anomalies, may vary with race, gender, and age [6-11]. Numerous pieces of research have proven this. Examples such as talons cusp and peg laterals are more common in permanent teeth than in primary teeth. Supernumerary teeth were more common in whites than in blacks, and anomalies such as talons cusp and supernumerary teeth are more common in men [9-15]. However, these anomalies may be present as an individual trait or in association with other conditions. Syndromes such as micrognathia and U-shaped cleft palate are often associated with Pierre-Robin Syndrome. Microdontia and peg laterals are often associated with SaethreChotzen Syndrome, and supernumerary teeth are associated with Gardner’s Syndrome [16,17].

Although research has described the prevalence of oral developmental anomalies, none has specifically 


\section{Cureus}

investigated clinically manifested developmental anomalies and their distribution among gender. Hence this study aims to establish more reliable data of the prevalence of clinically manifested developmental anomalies for the cognizance of the society under the following criteria: one, to evaluate the most prevalent developmental anomaly; and two, to evaluate the frequency of prevalence of developmental anomalies between gender.

\section{Materials And Methods}

This epidemiological study was conducted in the Department of Oral Medicine and Radiology, Faculty of Dental Sciences, Sri Ramachandra Institute Of Higher Education and Research, after obtaining ethical clearance from the Institutional Ethics Committee of Sri Ramachandra Institute of Higher Education and Research.

The study population included patients aged 18 to 20 years. Patients excluded from the study were those who had systemic medical conditions and those who needed emergency treatment.

The sample size was estimated by the use of the Leslie Fischer's formula for study populations of more than 20,000 at a $95 \%$ confidence level with a $50.0 \%$ prevalence and a degree of error set at 0.05 ; the sample size estimate was 323 , but the sample size was increased to 500 patients.

Data were collected via clinical examination. The anomalies included supernumerary teeth (i.e., the presence of additional teeth that can be present anywhere in the oral cavity), talon cusps (i.e., a cusp-like projection in the lingual surface of anterior teeth), peg laterals (i.e., the lateral labial surfaces of maxillary lateral incisors are peg-shaped), paramolars (i.e., supernumerary molars present buccally or lingual to molars), mesiodens (i.e., supernumerary incisors present between maxillary central incisors), microdontia (i.e., the size of the teeth is smaller than the prescribed size) [18].

Intra-examiner accuracy testing was performed to calibrate the principal investigator on the consistency of diagnosis for these developmental anomalies. The test was done by examining the clinical photograph of various clinically manifested developmental anomalies. The scoring for each of the anomalies identified correctly was recorded. The intra-examiner accuracy score was sufficiently high.

The collected data were tabulated based on sex, age, and jaw variance using the chi-square test. These data were then compiled into Table 1 and Figure 1.

\begin{tabular}{|c|c|}
\hline Variable & Frequency \\
\hline \multicolumn{2}{|l|}{ Gender } \\
\hline Men & $57.1 \%$ \\
\hline Women & $42.9 \%$ \\
\hline \multicolumn{2}{|l|}{ Age Group } \\
\hline 18-28 years & $36.7 \%$ \\
\hline 28-38 years & $46.9 \%$ \\
\hline $38-50$ years & $16.3 \%$ \\
\hline \multicolumn{2}{|l|}{ Anomalies } \\
\hline Total Anomalies Detected & $12 \%$ \\
\hline Supernumerary teeth & $4.25 \%$ \\
\hline Paramolars & $3 \%$ \\
\hline Peg laterals & $1.2 \%$ \\
\hline Talons cusp & $0.8 \%$ \\
\hline Mesiodens & $2.5 \%$ \\
\hline Microdontia & $0.25 \%$ \\
\hline
\end{tabular}

TABLE 1: Prevalence of developmental anomalies in a population of 500 patients 


\section{Cureus}

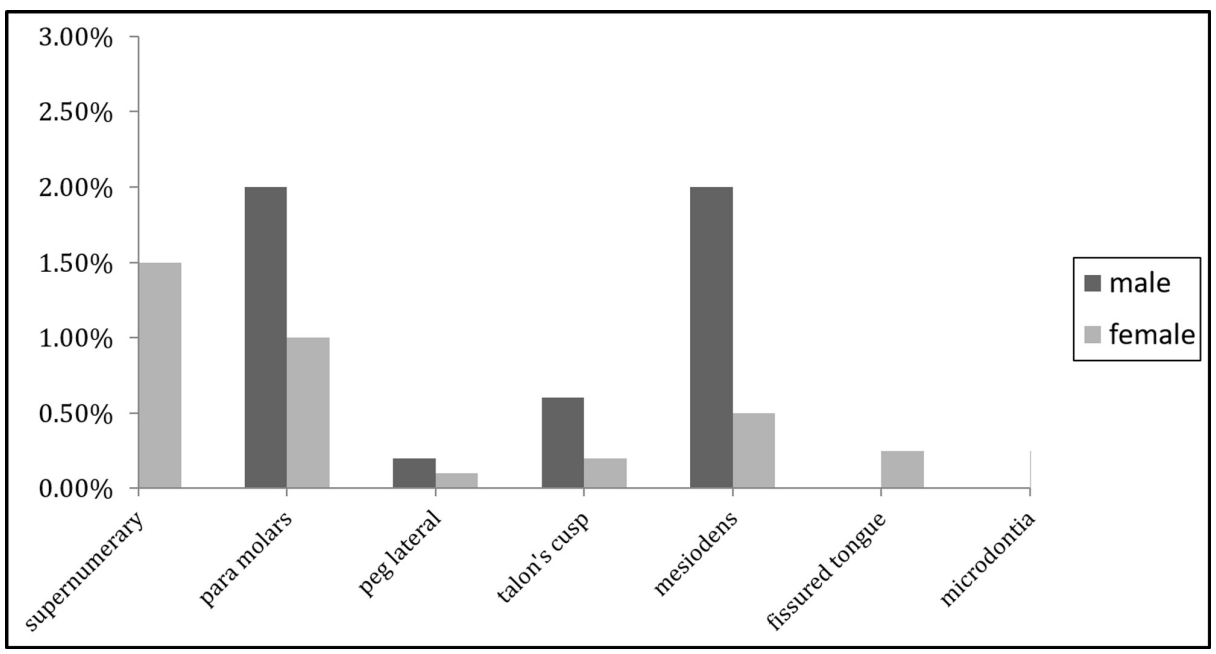

FIGURE 1: Distribution of anomalies among genders

\section{Results}

From the clinical study of 500 patients, it was noted that $12.2 \%$ (Table 1 ) of the study population were detected with anomalies. Of these, $57.1 \%$ were men. A detailed listing of the results is given in Table 1 . Clinical photographs of the anomalies seen are provided in Figure 2.

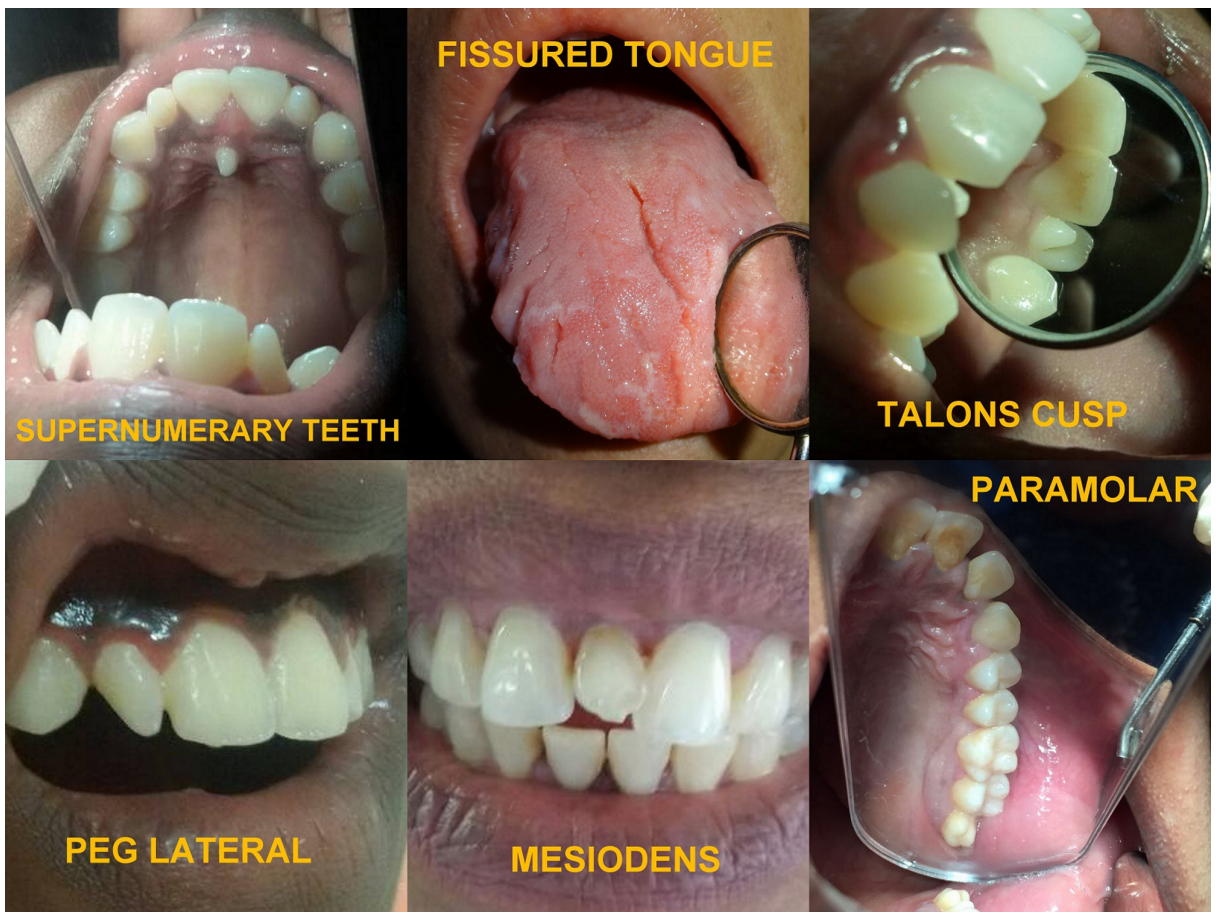

FIGURE 2: Photographic representation of the developmental anomalies

A graphical representation of the percentage of orofacial developmental anomalies is shown in Figure 1 .

\section{Discussion}

Developmental anomalies of the oral cavity are mainly congenital defects that often compromise the function of the oral cavity and the aesthetics of an individual. We, as health care providers, should identify these anomalies as early as possible so that functional and aesthetic rehabilitation of the dentition can be established early. Through this study, we aimed to know the prevalence of clinically manifested anomalies in a south Indian population for the future development and welfare of the society.

In our study, the prevalence of anomalies was $12.2 \%$. Of these, $57.1 \%$ were men, and $43.9 \%$ were women. 
These results match with results reported by Guttal et al. (11\%) and Gupta et al. (12\%) in studies conducted during 2010 and 2011, respectively $[6,13]$.

The most prevalent anomaly found was supernumerary teeth (4.25\%); other frequently found anomalies were paramolars and mesiodens. These findings are in keeping with the results of other studies by Ooshima et al. in Japan and Mohanty et al. in the United States [9,19]. Research by Hamasha et al. who carried out similar epidemiological studies, revealed that certain anomalies like microdontia and talons cusp showed the least prevalence among all other anomalies [20]. This also fell in line with our research.

Several factors contribute to developmental anomalies of the tongue. For example, exposure of pregnant women to environmental factors like teratogenic drugs and radiation, consumption of high fluorine diet, smoking, and alcohol may increase the risk of developmental tongue anomalies in newborns. When environmental factors impact pregnant women, it has been demonstrated to cause developmental anomalies of the oral cavity, specifically those pertaining to the size and shape of the teeth in progeny [21-24].

The higher prevalence of tongue developmental disorders in men is often due to the presence of one sexlinked X-chromosome [25]. This study also noted that the number of anomalies recorded found in maxilla exceeded the number of anomalies detected in the mandible (67.3\% in the maxilla and $32.6 \%$ in the mandible).

\section{Conclusions}

In spite of being asymptomatic, these developmental defects can lead to serious problems including delayed, no eruption, or impaction of the supernumerary or normal teeth (or tooth); attrition; reduced aesthetics and tongue space; temporomandibular joint discomfort, malocclusion, changes in face profile, and also increase the risk of caries and periodontal issues. It is likewise the case that supernumerary teeth, with a sharp incisal or occlusal tip, can cause constant irritation that can lead to malignant transformation of the mucosa. Therefore, proper care of these anomalies should be taken in order to avoid serious orofacial problems. In this study, we were able to educate patients with anomalies about the long-term effects of these anomalies on their body and systemic functions.

\section{Additional Information \\ Disclosures}

Human subjects: Consent was obtained by all participants in this study. Ethics Committee for Students Projects, Sri Ramachandra University issued approval CSP/17/MAY/58/168. The Ethics Committee for the students proposals, Sri Ramachandra University, acknowledges you for submitting the above proposal which was discussed in its meeting held on 23.05.2017. After discussion, the committee decided to approve the proposal. . Animal subjects: All authors have confirmed that this study did not involve animal subjects or tissue. Conflicts of interest: In compliance with the ICMJE uniform disclosure form, all authors declare the following: Payment/services info: All authors have declared that no financial support was received from any organization for the submitted work. Financial relationships: All authors have declared that they have no financial relationships at present or within the previous three years with any organizations that might have an interest in the submitted work. Other relationships: All authors have declared that there are no other relationships or activities that could appear to have influenced the submitted work.

\section{References}

1. Wadhwa PD, Buss C, Entringer S, Swanson J: Developmental origins of health and disease: brief history of the approach and current focus on epigenetic mechanisms. Semin Reprod Med. 2009, 27:358-368. http://doi.org/10.1055/s-0029-1237424

2. White SC, Pharoah MJ: Dental anomalies. Oral Radiology Principles and Interpretation. Mosby (ed): Elsevier, St. Louis; 2004. 8:330-365.

3. Chaste P, Leboyer M: Autism risk factors: genes, environment, and gene-environment interactions. Dialogues Clin Neurosci. 2012, 14:281-292.

4. Shalini Gupta: Distribution of various developmental dental anomalies in uttar pradesh: a hospital based study. J Dent Sci. 2014, 2:1-7.

5. Proffit WR: The development of orthodontic problems . Contemporary Orthodontics. Mosby (ed): Elsevier, St. Louis; 1997. 5:768.

6. Gupta SK, Saxena P, Jain S, Jain D: Prevalence and distribution of selected developmental dental anomalies in an Indian population. J Oral Sci. 2011, 53:231-238. https://doi.org/10.2334/josnusd.53.231

7. Shah RM, Boyd MA, Vakil TF: Studies of permanent tooth anomalies in 7886 Canadian individuals. I: impacted teeth. Dent J. 1978, 44:262-264.

8. Al-Emran S: Prevalence of hypodontia and developmental malformation of permanent teeth in Saudi Arabian schoolchildren. Br J Orthod. 1990, 17:115-118. https://doi.org/10.1179/bjo.17.2.115

9. Ooshima T, Ishida R, Mishima K, Sobue S: The prevalence of developmental anomalies of teeth and their association with tooth size in the primary and permanent dentitions of 1650 Japanese children. Int J Paediatr Dent. 1996, 6:87-94. https://doi.org/10.1111/j.1365-263X.1996.tb00218.x

10. Thongudomporn U, Freer TJ: Prevalence of dental anomalies in orthodontic patients . Aust Dent J. 1998, 43:395-398. 
11. Bruce C, Manning-Cox G, Stanback-Fryer C, Banks K, Gilliam M: A radiographic survey of dental anomalies in Black pediatric patients. NDA J. 1994, 45:6-13.

12. Ardakani FE, Sheikhha MH, Ahmadi H: Prevalence of dental developmental anomalies: a radiographic study . Community Dent Health. 2007, 24:140-144.

13. Guttal KS, Naikmasur VG, Bhargava P, et al.: Frequency of developmental dental anomalies in the Indian population. Eur J Dent. 2010, 4:263-269.

14. Dankner E, Harari D, Rotstein I: Dens evaginatus of anterior teeth. Literature review and radiographic survey of 15,000 teeth. Oral Surg Oral Med Oral Pathol Oral Radiol Endod. 1996, 81:472-475. https://doi.org/10.1016/s1079-2104(96)80027-8

15. Sharma G, Nagpal A: Talon cusp: a prevalence study of its types in permanent dentition and report of a rare case of its association with fusion in mandibular incisor. J Oral Dis. 2014, 595189:6.

16. Masood F, Benavides E: Alterations in tooth structure and associated systemic conditions . Radiol Clin North Am. 2018, 56:125-140. https://doi.org/10.1016/j.rcl.2017.08.009

17. Shprintzen: Pierre robin, micrognathia, and airway obstruction: the dependency of treatment on accurate diagnosis. Int Anesthesiol Clin. 1988, 26:64-7. https://doi.org/10.1097/00004311-198802610-00014

18. Shafer, Hine, Levy: Developmental disturbances of oral cavity. Shafer's Textbook of Oral Pathology. B Sivapathasundharam (ed): Elsevier, India; 2016. 8:1-62.

19. Mohanty R, Singh V, Dey AK, Behera S: A rare nonsyndromic case of adenomatoid odontogenic tumor associated with multiple impacted supernumerary teeth. Natl J Maxillofac Surg. 2019, 10:114-117. 10.4103/njms.NJMS_25_18

20. Hamasha AA, Safadi RA: Prevalence of talon cusps in Jordanian permanent teeth: a radiographic study . BMC Oral Health. 2010, 10:6. 10.1186/1472-6831-10-6

21. Yassin SM: Prevalence and distribution of selected dental anomalies among Saudi children in Abha, Saudi Arabia. J Clin Exp Dent. 2016, 8:485-490. https://doi.org/10.4317/jced.52870

22. Lassi ZS: Preconception care: caffeine, smoking, alcohol, drugs and other environmental chemical/radiation exposure. Reprod Health. 2014, 11:1-12. https://doi.org/10.1186/1742-4755-11-S3-S6

23. Zhu H, Shang D, Sun M, et al.: X-linked congenital hypertrichosis syndrome is associated with interchromosomal insertions mediated by a human-specific palindrome near SOX3. Am J Hum Genet. 2011, 88:819-826. https://doi.org/10.1016/j.ajhg.2011.05.004

24. Tredwin CJ, Scully C, Bagan-Sebastian JV: Drug-induced disorders of teeth. J Dent Res. 2005, 84:596-602. https://doi.org/10.1177/154405910508400703

25. Weinhold, B: Environmental factors in birth defects: what we need to know . Environ Health Perspect. 2009, 117:440. https://doi.org/10.1289/ehp.117-a440 